\title{
CARACTERIZAÇÃO E CLASSIFICAÇÃO DE SOLOS TIOMÓRFICOS DA VÁRZEA DO RIO CORURIPE, NO ESTADO DE ALAGOAS(1)
}

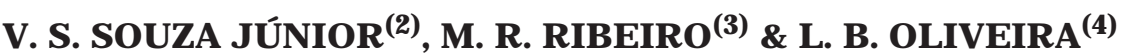

\begin{abstract}
RESUMO
Com objetivo de caracterizar e classificar solos com problemas de tiomorfismo na várzea do rio Coruripe, Zona Úmida Costeira do estado de Alagoas, foram selecionados seis perfis na área pertencente à Usina Coruripe, onde está instalado um sistema de drenagem. Os solos foram morfologicamente caracterizados e, nas amostras de cada horizonte, foram determinados: granulometria, densidade global e das partículas, porosidade total, $\mathrm{pH}\left(\mathrm{H}_{2} \mathrm{O}\right.$ e $\mathrm{KCl}$ ), matéria orgânica, bases trocáveis e CTC, sulfato solúvel e condutividade elétrica. As diferenças entre os perfis estudados foram determinadas principal mente pela espessura, teor de carbono orgânico e grau de decomposição do material orgânico dos horizontes superficiais e refletem o arranjamento dos solos na paisagem. Os solos apresentaram altos teores de matéria orgânica, com valores entre 17 a $77 \%$ da massa do solo, que determi naram as propriedades físicas, a despeito da textura muito argi losa dos perfis. Os horizontes sulfúricos ocorreram à profundidade entre 45 e $90 \mathrm{~cm}$, nos Gleissolos, e entre 15 e $43 \mathrm{~cm}$, nos Organossolos. A capacidade de troca de cátions é muito alta em todos os perfis em virtude dos altos teores de matéria orgânica. Hidrogênio e alumínio são os cátions dominantes, conferindo o caráter distrófico aos perfis 2, 3 e 6 e álico aos perfis 1, 4 e 5. A condutividade elétrica apresentou valores elevados $\left(\geq 4,0 \mathrm{dS} \mathrm{m}^{-1}\right)$ em apenas alguns dos horizontes sulfúricos, em virtude da presença do hidrogênio em solução, liberado com a oxidação da pi rita e formação de ácido sulfúrico. Com base nos resultados obtidos, os solos estudados foram classificados como: Gleissolo Tiomórfico Hístico típico álico; Gleissolo Tiomórfico Húmico típico distrófico; Organossolo Tiomórfico Sáprico térrico distrófico; Organossolo Tiomórfico Sáprico térrico álico; Organossolo Tiomórfico Hêmico térrico álico; Organossolo Tiomórfico Hêmico térrico distrófico. Os critérios estabelecidos no Sistema Brasileiro de Classificação de Solos mostraram-se adequados à classificação dos solos estudados.
\end{abstract}

Termos de indexação: Gleissolos, Organossolos, Taxonomia de solos.

\footnotetext{
(1) Parte da Tese de Mestrado do primeiro autor, apresentada ao Programa de Pós-Graduação em Agronomia, Ciência do Solo da Universidade Federal Rural de Pernambuco - UFRPE. Recebido para publicação em maio de 2000 e aprovado em março de 2001.

(2) Engenheiro-Agrônomo. Rua Maria Vicentina da Silva 64/04, Imbiribeira. CEP 51150-570 Recife (PE). E-mail: vsouzajr@yahoo.com

(3) Professor do Departamento de Agronomia, Área de Sol os, Universidade Federal Rural de Pernambudo - UFRPE. Rua Dom Manoel de Medeiros S/N, CEP 52171-900 Recife (PE). Bolsista do CNPq. E-mail: rosas@truenet.com.br

(4) Mestrando do Programa de Pós-Graduação em Agronomia - Ciência do Solo, UFRPE. E-mail: Ibdeoliveira@yahoo.com.br
} 


\title{
SUMMARY: CHARACTERIZATION AND CLASSIFICATION OF ACID SULFATE SOILS IN LOWLANDS OF CORURIPE RIVER VALLEY, ALAGOAS, BRAZIL
}

\begin{abstract}
Six soil profiles wereselected in a drained lowland area at CoruripeSugarmill, aiming to characterize acid sulfate soils occurring in the lowplain of the Coruripe River Valley, in thecoastal humid zone of thestate of Alagoas. Thesoil s weremorphol ogical ly characterized, and samples were taken from each horizon to determine particle size distribution, bulk and particledensity, total porosity, $\mathrm{pH}\left(\mathrm{H}_{2} \mathrm{O}\right.$ and $\left.\mathrm{KCl}\right)$, organic matter, exchangeable bases and CEC, soluble sulfate and el ectrical conductivity of the saturation extract. The differences between the studied soils were mainly determined by the thickness, amount and degree of decomposition of theorganic matter in thesurfacehorizons, and aredependent on the position of the soils in the landscape Large amounts of organic matter were found , with values between 15 and $77 \%$ of the soil weight, and have great influence on physical properties, despite the heavy clay texture of the soils. The sulfuric horizons were found to be between 45 and $90 \mathrm{~cm}$ depth, in the Gleisols, and between 15 and $43 \mathrm{~cm}$ depth in the Organosols. The cation exchange capacity is very high in all soil profiles, due to the large amounts of organic matter. Exchangeable aluminum and hidrogen were the dominant cations resulting in the distrophic character of profiles 2, 3 and 6, and allic character of profiles 1,4 and 5 . The electrical conductivity showed high values $\left(\geq 4,0 \mathrm{dS} \mathrm{m}^{-1}\right)$ in some of thesulfuric horizons dueto the presence of $\mathrm{H}^{+}$in thesoil sol ution related to theformation of sulfuric acid from oxidation of sulfide. According to the results, the studied acid sulfate soils were classified in the Brazilian system as: Gleissol o Tiomórfico Hístico típico, álico; Gleissolo Tiomórfico Húmico típico, distrófico; Organossolo Tiomórfico Sáprico térrico, distrófico; Organossol o Tiomórfico Sáprico térrico, álico; Organossolo Tiomórfico Hêmico térrico, álico; Organossolo Tiomórfico Hêmi co térrico, distrófico. The criteria established in the Brazilian System of Soil Classification appeared to be adequate to the classification of the studied soils.
\end{abstract}

Index terms: acid sulfate soils, Gleisols, Organosols, Soil taxonomy.

\section{NTRODUÇÃO}

Sob a denominação de solos tiomórficos são agrupados, atualmente, solos das classes dos Gleissolos e Organossolos que apresentam um horizonte sulfúrico gerado pela oxidação de materiais sulfídricos (EMBRAPA, 1999). Com a drenagem do terreno, o material sulfídrico sofre forte oxidação e os sulfetos transformam-se em sulfatos que, por sua vez, favorecem a formação de ácido sulfúrico, resultando em brusco abaixamento do $\mathrm{pH}$ dos solos para valores inferiores a 3,5. Nestas condições, as culturas estão sujeitas a um estresse fisiológico que é atribuído principal mente à toxidez do alumínio e a deficiências nutricionais, principalmente de fósforo.

De forma geral, estes solos ocorrem em todas as zonas climáticas do planeta, geralmente em áreas costeiras, desenvolvendo-se em sedimentos flúviomarinhos recentes (Pons, 1973). Também ocorrem como material fóssil em minas de carvão, ouro e urânio (Seiller, 1992).

São raras as informações existentes sobre sua ocorrência no Brasil. Segundo Oliveira et al. (1992), há dados de perfis descritos no município de Campos (RJ ), no litoral sul do estado de São Paulo e no Rio
Grande do Sul. Solos tiomórficos também foram estudados no Espírito Santo (Lani, 1998) e em Alagoas (Usina Coruripe, 1997).

Com relação à classificação brasileira, os solos tiomórficos estão agrupados, segundo o Sistema Brasileiro de Classificação de Sol os, nas subordens dos Gleissol os Tiomórficos eOrganossol os Tiomórficos, que apresentam um horizonte sulfúrico e, ou, materiais sulfídricos dentro de $100 \mathrm{~cm}$ da superfície do solo (EMBRAPA, 1999).

Por se tratar de solos pouco conhecidos, particularmente na região nor deste, o objetivo deste trabalho foi caracterizar e classificar os solos com problemas detiomorfismo na várzea do rio Coruripe, no estado de Alagoas, visando fornecer subsídios à exploração agrícola sustentável desses solos e contribuir para o aprimoramento do Sistema Brasileiro de Classificação de Solos.

\section{MATERIAL E MÉTODOS}

\section{O meio físico}

A área estudada localiza-se em terras da Usina Coruripe, no município de mesmo nome, zona 
fisiográfica do Litoral, estado de Alagoas, cujas coordenadas são $10^{\circ} 08^{\prime}$ de latitude sul e $36^{\circ} 11^{\prime}$ de longitude a oeste de Greenwich. Corresponde a uma parte da várzea do baixo curso do rio Coruripe, que abrange uma área de 1.760 ha, distribuída deforma contínua ao longo da planície de inundação do rio, onde, em 1995, foi construídoumsistema dedrenagem e estabelecida a cultura da cana-de-açúcar. A drenagem destas áreas sem um conhecimento mais aprofundado dos solos promoveu a formação de horizontes sulfúricos, com reflexos sobre o desenvolvimento da cultura nos trechos mais afetados.

O clima da área enquadra-se, de acordo com a classificação de Köppen, notipo As', ou seja , quente e úmido com chuvas de outono-inverno. As preci pitações apresentam média anual da ordem de $1.400 \mathrm{~mm}$, sendo o trimestre mais chuvoso correspondente aos meses de maio a julho. O trimestre mais seco recai nos meses de outubro a dezembro. A temperatura média anual é de $25^{\circ} \mathrm{C}$, com uma amplitude térmica anual muito pequena, da ordem de $3^{\circ} \mathrm{C}$, devido ao efeito termorregulador do oceano. O regime hídrico dos sol os estudados é, entretanto, comandado pela presença do lençol freático, atualmente mantido a uma profundidade entre 20 e $60 \mathrm{~cm}$ por meio de um sistema de drenagem, com drenos abertos, controlado por comportas e bombeamento. Toda várzea é protegi da contra enchentes por um sistema de diques e, apenas para permitir a col heita, éfeito maior rebaixamento do nível do lençol freático.

Os solos estudados são predominantemente desenvolvidos de materiais recentes do Quaternário (Holoceno), constituídos por sedimentos aluviais e depósitos orgânicos, da planície de inundação do rio Coruripe, que entalha os Tabuleiros Costeiros do GrupoBarreiras. Os sedimentos aluviais, muitas vezes apresentando camadas intercaladas com materiais orgânicos, são predominantemente argil osos e muito argil osos e dãoformação aos Gleissolos. Os materiais orgânicos turfosos estão relacionados com a parte da várzea mais próxima ao mar e mais encharcada e dão origem a solos orgânicos, geralmente tiomórficos (Usina Coruripe, 1997).

O relevo da área estudada é característico de várzea, apresentando-se predominantemente plano, com trechos levemente deprimidos que formam lagoas temporárias, muitas delas entupidas pela sistematização do terreno.

\section{Métodos}

Com base no levantamento detalhado de solos da várzea (U sina Coruripe, 1997), foram feitos dois transectos, visando identificar os fatores responsáveis pelo arranjamento e distribuição dos solos na paisagem. Foram selecionados seis locais para descrição e col eta dos perfis, em trechos típicos das áreas com tiomorfismo, e abrangendo os diferentes tipos de solos tiomórficos.
Os perfis foram descritos segundo o manual de descrição e col eta de sol o no campo (Lemos \& Santos, 1996), em março de 1998, final do período seco, após a colheita. O lençol freático estava mantido à profundidade de 20 a $30 \mathrm{~cm}$, nos Organossolos, e entre 40 e $60 \mathrm{~cm}$, nos Gleissolos. Apenas um dos perfis não apresentava lençol freático até os $150 \mathrm{~cm}$. Após descrição dos perfis, foram col etadas amostras deformadas e indeformadas por horizonte, visando à caracterização física e química dos solos. As amostras deformadas foram pré-tratadas, secas ao ar, destorroadas e passadas em peneira de $2 \mathrm{~mm}$, para a obtenção da TFSA.

As análises físicas incluíram as determinações de: granulometria (após destruição da matéria orgânica), densidade global e porosidade total, de acordo com EMBRAPA (1997), e densidade das partículas, pelo método preconizado por Lambe (1951), utilizando água e aquecimento.

As análises químicas foram as seguintes: pH (em água e $\mathrm{KCl}$, na proporção de 1:1), complexo sortivo, fósforo disponível, matéria orgânica, nitrogênio total, sulfato solúvel e condutividade elétrica do extrato da pasta saturada. Nestas, empregaram-se os métodos propostos pela EMBRAPA (1997), com exceção da matéria orgânica e do sulfato solúvel $\left(\mathrm{SO}_{4}{ }^{2-}\right)$. A matéria orgânica foi determinada por combustão seca a 375C , conforme método citado por Dent (1986), que considera a determinação por oxidação pel o dicromato inadequada para sol os com sulfetos, em virtude da reação do dicromato com a pirita. O sulfato solúvel foi determinado por colorimetria, pela reação com o cromato de bário, com liberação do íon cromato, de cor amarela, em quantidade proporcional à deíons sulfato, de acordo com método descrito por Dewis \& Freitas (1970).

As análises foram real izadas com três repetições para as análises físicas e duas repetições para as anál ises quími cas, sendo os resultados representados pelas médias.

\section{RESULTADOS E DISCUSSÃO}

\section{Propriedades morfológicas e posição dos solos na paisagem}

As descrições morfológicas dos perfis estudados podem ser observadas no quadro 1. De maneira geral, os solos apresentam uma morfologia semelhante em profundidade, característica do horizonte Cgj, detextura argil osa ou muito argilosa, afetado pela presença do lençol freático. A diferenciação observada entre os perfis édeterminada pela espessura, pel o teor e pel o grau de decomposição da matéria orgânica dos horizontes superficiais, que, por sua vez, refletem as condições de drenagem do local , favorecendo a formação dehorizonte A húmico ou horizonte hístico. 


\section{Quadro 1. Características morfológicas dos solos}

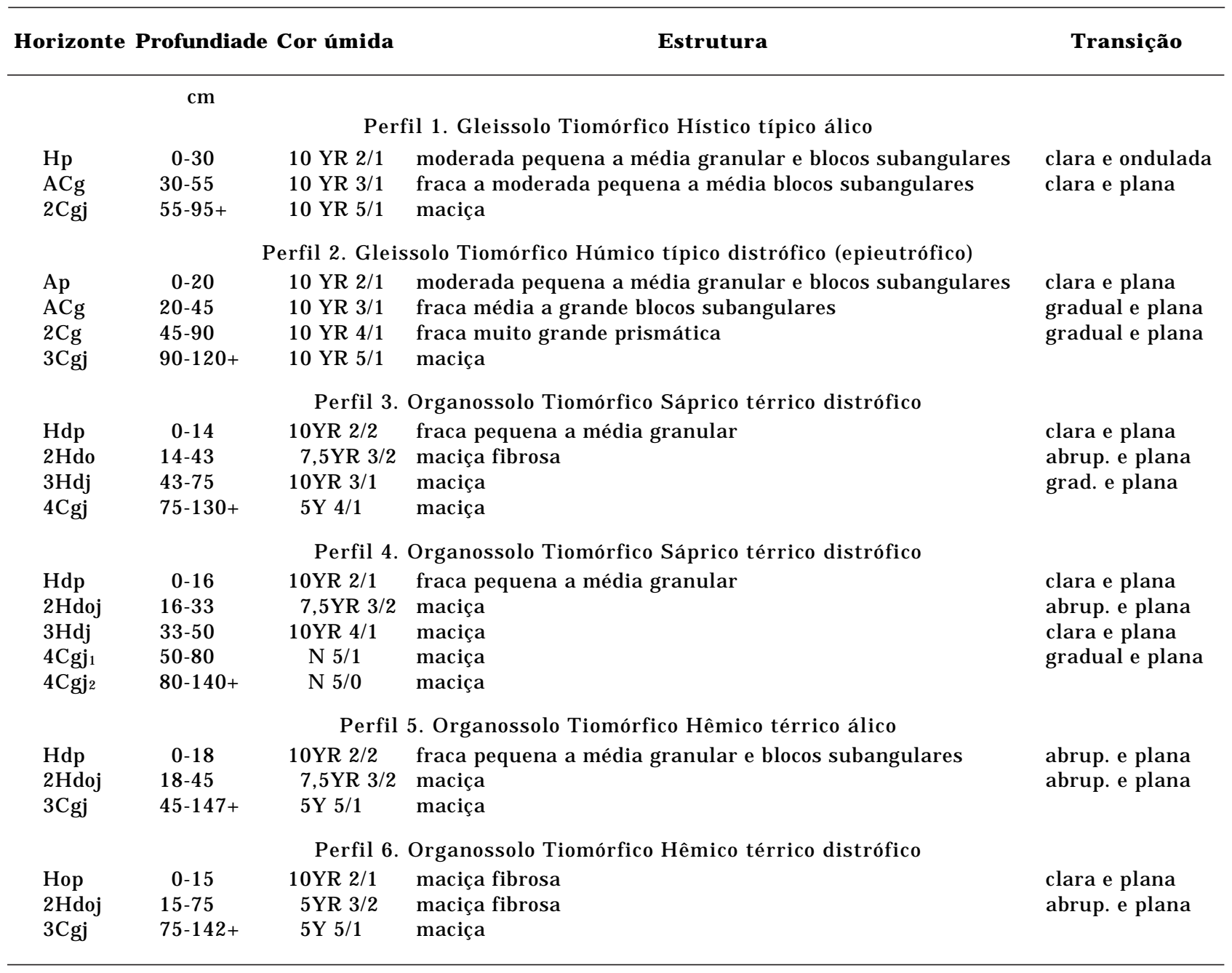

Os Gleissolos, que mostram mel hor condição de drenagem que os Organossolos, estão relacionados com a margem esquerda do rio, que se apresenta mais alta e menos sujeita a inundações. Apresentam seqüência de horizontes $\mathrm{Hp}, \mathrm{ACg}$ e 2Cgj (perfil 1) e $\mathrm{Ap}, \mathrm{ACg}, 2 \mathrm{Cg}$ e $3 \mathrm{Cgj}$ (perfil 2), com transições claras entre os horizontes superficiais e graduais em profundidade.

O perfil 1 apresenta um horizonte hístico com $30 \mathrm{~cm}$ de espessura, e o horizonte $2 \mathrm{Cgj}$ tem início a $55 \mathrm{~cm}$ de profundidade. O perfil 2 revela um horizonte A húmico e o horizonte $3 \mathrm{Cgj}$ ocorrea uma profundidade de $90 \mathrm{~cm}$. Esta variação entre os perfis de Gleissolos está relacionada com o relevo, que controla a drenagem, localizando-se o perfil $1 \mathrm{em}$ posição mais baixa e mais afastada da cal ha do rio, próximo ao sopé da encosta, enquanto o perfil 2 está numa posição de ombreira, mais alta e próxima à calha do rio. A melhor condição de drenagem é corroborada pela profundidade do lençol freático que se encontrava a $40 \mathrm{~cm}$ no perfil 1, e a $60 \mathrm{~cm}$ no perfil 2, por ocasião da descrição dos perfis, como também pela profundidade do horizonte sulfúrico (Figura 1).

Os dois perfis são mal drenados e apresentam-se muito semelhantes com relação às demais características morfológicas. Observam-se cores preto (10YR 2/1) e cinzento muito escuro (10YR 3/1), nos dois primeiros horizontes, e cinzento (10YR 5/1), nos horizontes Cgj, com mosqueado geralmente bruno-forte etextura muito argilosa ao longo de todo o perfil. Em virtude dos altos teores de matéria orgânica dos horizontes superficiais, constatou-se grande divergência entre as determinações de laboratório e as classes texturais determinadas em campo, que foram definidas como franco-arenosa ou franca, e que melhor refletem a condição física e o comportamento destes horizontes. 


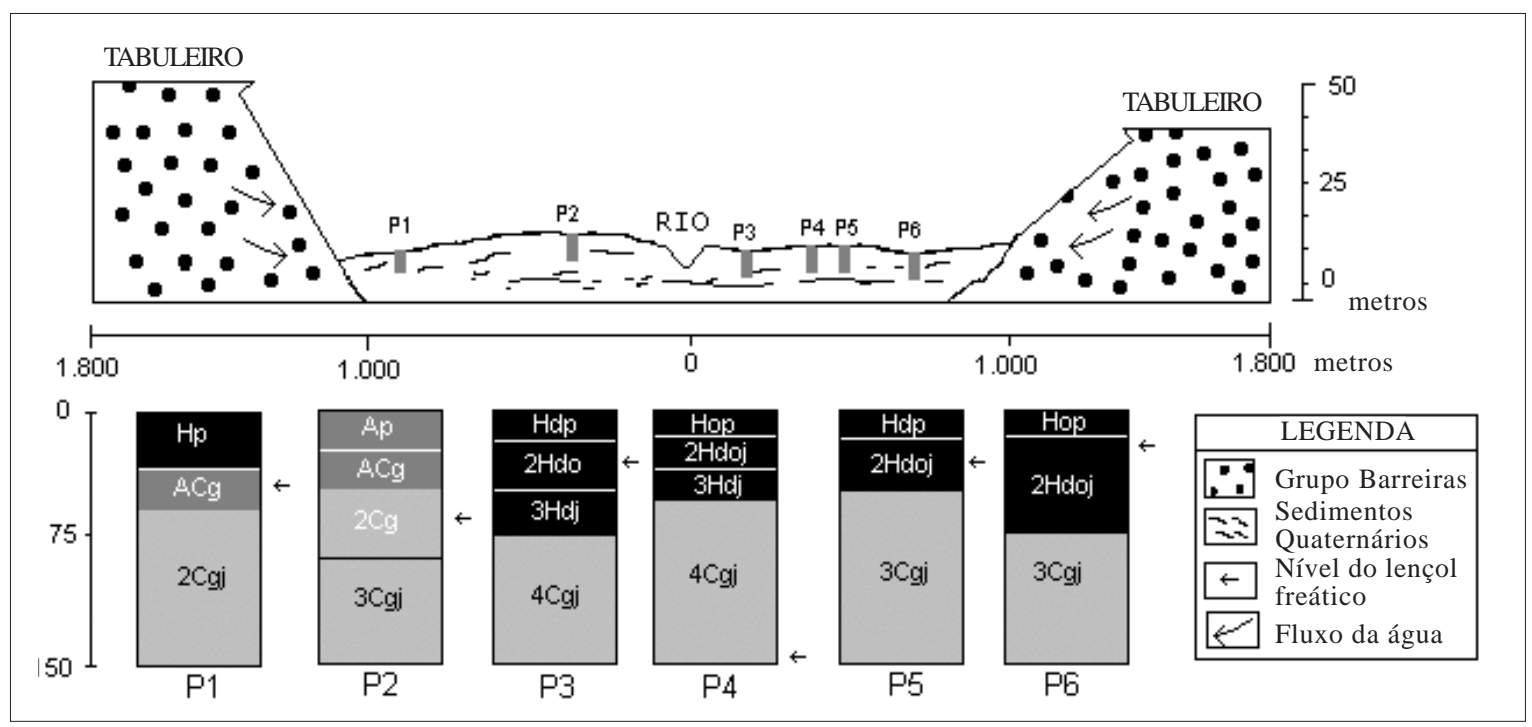

Figura 1. Localização dos perfis estudados em relação à topografia e à geologia.

A estrutura e a consistência dos Gleissolos estudados também são muito semel hantes, apresentando-se moderada, pequena a média granular e em blocos subangulares nos horizontes superficiais, com consistência ligeiramente dura ou dura, friável, ligeiramente plástica e ligeiramente pegajosa, o quevem corroborar a influência da matéria orgânica no comportamento físico destes horizontes.

Os Organossolos ocupam a margem direita da várzea, mais baixa e mais inundável, eapresentam duas seqüências de variações de espessura e principalmente do teor e estádio de decomposição dos materiais orgânicos. A espessura da camada orgânica varia de 45 a $75 \mathrm{~cm}$ e normalmente é determinada pela maior restrição à drenagem, o que promove menor taxa de decomposição do material orgânico, favorecendo o seu acúmulo (F igura 1).

Com exceção da espessura, os solos orgânicos estudados apresentam características morfológicas muito semel hantes. As cores são muito escuras nos horizontes superficiais, no matiz 10YR, val or 2 e cromas entre 1 e 2, passando a col orações brunadas escuras, nos matizes 7,5YR e 5YR, val or 3 ecroma 2, com mosqueado geral mente bruno forte. O horizonte glei tem cor cinzenta na matiz $5 Y$, ou neutra ( $\mathrm{N} \mathrm{5/0)}$ e ocorre à profundidade entre 45 e $75 \mathrm{~cm}$, definindo os perfis estudados como térricos no $4^{\circ}$ nível categórico (subgrupo). A textura émuito argil osa ou argilosa nos perfis 3 e 4, e franco-argilosa e franca, passando a muito argilosa nos perfis 5 e 6 . A textura de campo dos horizontes orgânicos foi determinada como franco-arenosa ou franca em todos os perfis, decorrente da influência de percentagens de matéria orgânica ainda maiores que nos Gleissolos.

Os horizontes superficiais dos organossolos apresentaram estrutura fraca pequena a média granular nos perfis 3, 4 e 5 (Hdp), ao passo que o horizonte Hop do perfil 6 apresentou ausência de estrutura, sendo descrito como maciço fibroso, mais compatível com o maior teor e pouco grau de decomposição do material orgânico. N os horizontes orgânicos subjacentes, a estrutura foi considerada maciça fibrosa ou si mpl esmente maciça, quetambém foi observada nos horizontes Cgj. Deve-se levar em consideração que o grau de umidade do horizonte gl ei dificultou a observação correta da estrutura.

A consistência úmida, também muito uniforme nos perfis estudados, apresentou-se friável a firme na superfíciee, geralmente, muitofirmeno horizonte glei. A consistência mol hada, ligeiramente plástica e ligeiramente pegajosa no horizonte superficial, devido à matéria orgânica, passou a muito plástica e muito pegajosa no horizonte $\mathrm{Cg}$.

\section{Propriedades físicas}

De acordo com os resultados da composição granul ometrica apresentados no quadro 2, observase um predomínio da fração argila, ocorrendo as classes texturais muito argilosa e argila em praticamente todos os perfis estudados, com teores de argila que variaram entre $442 \mathrm{e}^{2} 903 \mathrm{~g} \mathrm{~kg}^{-1}$ de solo, característica compatível com a natureza dos sedimentos al uviais depositados nos vales dos baixos cursos dos rios, onde a proximidade do nível de base promove a redução da correnteza e favorece a deposição de materiais finos.

Apenas os perfis 5 e 6 , de Organossolos Tiomórficos Hêmicos, apresentaram texturas franco-argil osas e franca nos horizontes superficiais $\mathrm{Hdp}$ ou Hop e $2 \mathrm{H}$ doj, com teores de argila que variaram de 211 a $378 \mathrm{~g} \mathrm{~kg}^{-1}$ de solo. Estes perfis, superficialmente menos argil osos, estão relacionados com as posições 
Quadro 2. Propriedades físicas dos solos estudados

\begin{tabular}{|c|c|c|c|c|c|c|c|c|}
\hline \multirow{2}{*}{ Horizonte } & \multirow{2}{*}{ Profundidade } & \multicolumn{3}{|c|}{ Fração granulométrica } & \multirow{2}{*}{ Classe textural } & \multirow{2}{*}{$\begin{array}{l}\text { Densidade } \\
\text { global }\end{array}$} & \multirow{2}{*}{$\begin{array}{c}\text { Densidade } \\
\text { da partícula }\end{array}$} & \multirow{2}{*}{$\begin{array}{c}\text { Porosidade } \\
\text { total }\end{array}$} \\
\hline & & Areia & Silte & Argila & & & & \\
\hline & $\mathrm{cm}$ & \multicolumn{3}{|c|}{$\mathrm{g} \mathrm{kg}^{-1} \longrightarrow$} & & \multicolumn{2}{|c|}{$\mathrm{kg} \mathrm{dm}^{-3}$} & $\%$ \\
\hline \multicolumn{9}{|c|}{ Perfil 1. Gleissolo Tiomórfico Hístico típico álico } \\
\hline $\mathrm{Hp}$ & $0-30$ & 80 & 182 & 738 & Muito Argilosa & 0,77 & 2,32 & 66 \\
\hline $\mathrm{ACg}$ & $30-55$ & 110 & 213 & 678 & Muito Argilosa & 0,66 & 2,31 & 71 \\
\hline $2 \mathrm{Cgj}$ & $55-95+$ & 30 & 222 & 748 & Muito Argilosa & 0,92 & 2,45 & 63 \\
\hline \multicolumn{9}{|c|}{ Perfil 2. Gleissolo Tiomórfico Húmico típico distrófico (epieutrófico) } \\
\hline Ap & $0-20$ & 60 & 162 & 778 & Muito Argilosa & 0,78 & 2,27 & 66 \\
\hline $\mathrm{ACg}$ & $20-45$ & 110 & 172 & 718 & Muito Argilosa & 0,78 & 2,33 & 66 \\
\hline $2 \mathrm{Cg}$ & $45-90$ & 42 & 55 & 903 & Muito Argilosa & 0,73 & 2,50 & 71 \\
\hline $3 \mathrm{Cgj}$ & $90-120+$ & 80 & 363 & 558 & Argila & 1,04 & 2,35 & 56 \\
\hline \multicolumn{9}{|c|}{ Perfil 3. Organossolo Tiomórfico Sáprico térrico distrófico } \\
\hline $\mathrm{Hdp}$ & $0-14$ & 70 & 182 & 748 & Muito Argilosa & 0,63 & 2,22 & 72 \\
\hline H do & $14-43$ & 60 & 122 & 818 & Muito Argilosa & 0,46 & 2,60 & 82 \\
\hline 4Cgj & $75-130+$ & 90 & 372 & 538 & Argila & 1,09 & 2,53 & 57 \\
\hline \multicolumn{9}{|c|}{ Perfil 4. Organossolo Tiomórfico Sáprico térrico distrófico } \\
\hline $\mathrm{Hdp}$ & $0-16$ & 234 & 269 & 497 & Argila & 0,52 & 1,90 & 72 \\
\hline H doj & $16-33$ & 348 & 210 & 442 & Argila & 0,45 & 1,92 & 76 \\
\hline $\mathrm{Hdj}$ & $33-50$ & 150 & 292 & 558 & Argila & 0,53 & 2,42 & 78 \\
\hline $4 \mathrm{Cgj}_{1}$ & $50-80$ & 20 & 292 & 718 & Muito Argilosa & 0,65 & 2,56 & 75 \\
\hline $4 \mathrm{Cgj} \mathrm{j}_{2}$ & $80-140+$ & 50 & 162 & 788 & Muito Argilosa & 0,57 & 2,62 & 78 \\
\hline \multicolumn{9}{|c|}{ Perfil 5. Organossolo Tiomórfico Hêmico térrico álico } \\
\hline $\mathrm{Hdp}$ & $0-18$ & 390 & 292 & 318 & Franco Argilosa & 0,42 & 1,85 & 77 \\
\hline $2 \mathrm{H}$ doj & $18-45$ & 301 & 424 & 275 & Franca & 0,18 & 1,80 & 90 \\
\hline $3 \mathrm{Cgj}$ & $45-147+$ & 10 & 212 & 778 & Muito Argilosa & 0,61 & 2,83 & 79 \\
\hline \multicolumn{9}{|c|}{ Perfil 6. Organossolo Tiomórfico Hêmico térrico distrófico } \\
\hline Hop & $0-15$ & 390 & 232 & 378 & Franco Argi losa & 0,58 & 1,88 & 69 \\
\hline $2 \mathrm{H}$ doj & $15-75$ & 482 & 307 & 211 & Franca & 0,36 & 1,59 & 77 \\
\hline 3Cgj & $75-142+$ & 10 & 272 & 718 & Muito Argilosa & 1,07 & 2,48 & 57 \\
\hline
\end{tabular}

mais baixas, de pior drenagem, e com os teores mais elevados de matéria orgânica.

Os teores de areia são geralmente muito baixos e diminuem com a profundidade. A presença da fração areia só teve mai or expressão nos horizontes superficiais dos perfis 5 e6, quetambém apresentaram os maiores valores de silte ( $424 \mathrm{~g} \mathrm{~kg}^{-1}$ de solo).

Fato de grande importância, do ponto de vista da utilização agrícola, é que os altos teores de argila dos horizontes ecamadas superficiais $\mathrm{A}$ ou $\mathrm{H}$ têm sua influência nas propriedades físicas modificada pelo alto teor de matéria orgânica, que está presente em valores da ordem de 150,98 e 768,64 $\mathrm{g} \mathrm{kg}^{-1}$ de solo.

Com relação à densi dade gl obal e das partículas, os sol os ti omórficos estudados apresentaram val ores evariação influenciados pel os al tos teores de matéria orgânica, típicos desses solos.
Como mostra o quadro 2, a densidade global mostrou valores que variaram de 0,18 a $1,09 \mathrm{~kg} \mathrm{dm}^{-3}$ de solo. Nos horizontes orgânicos, os resultados variaram de 0,18 a 0,63 $\mathrm{kg} \mathrm{dm}^{-3}$, dependendo do teor e do grau de decomposição da matéria orgânica, correspondendo os valores mais baixos aos horizontes ou camadas com teores mais altos de matéria orgânica e caráter hístico. Tais resultados são compatíveis com os de Zelazny \& Carlisle (1974), que, estudando solos orgânicos da Flórida, observaram uma relação da densidade gl obal com o grau de decomposição da matéria orgânica, ondesolos mais decompostos apresentaram maior densidade. Resultados semel hantes foram encontrados por Conceição (1989), em solos orgânicos do Rio de J aneiro, e por Kämpf \& Schneider (1989), em solos orgânicos do Rio Grande do Sul. A baixa densidade global dos solos orgânicos deve ser levada em 


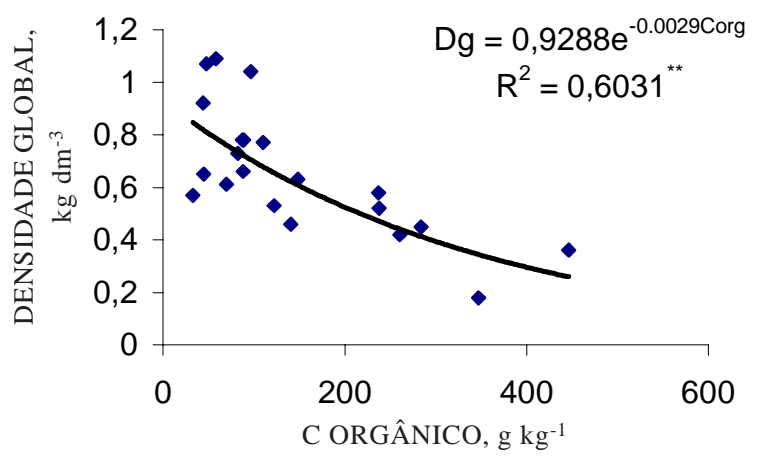

Figura 2. Correlação entre teores de carbono orgânico (CO) e densidade global (Dg) de solos tiomórficos da várzea do rio Coruripe (AL).

consideração quando da interpretação de resultados analíticos para comparação com solos de maior densidade.

Mesmo nos horizontes minerais, quecontêmal tos teores de argila, os níveis de matéria orgânica foram suficientes para promover uma densidade global, também baixa, variando de 0,57 a $1,09 \mathrm{~kg} \mathrm{dm}^{-3}$, dependendo do aumento dos teores da matéria orgânica. A figura 2 mostra a correlação significativa da densidade global com os teores de matéria orgânica dos solos.

Com relação à densidade das partículas, também influenciada pela presença da matéria orgânica, foram observados val ores entre 1,59 e 2,83 $\mathrm{kg} \mathrm{dm}^{-3}$, variando de forma inversamente proporcional aos teores da matéria orgânica.

A porosidade total, calculada com base na densidadeglobal edas partículas, mostrou percentuais muito altos, entre 56 e 90\%, variando conforme os teores da matéria orgânica e da fração argila, os valores mais baixos, correspondendo aos horizontes minerais mais profundos (Quadro 2). Conceição (1989) encontrou val ores bem semel hantes em Sol os Orgânicos e Gleissolos no Rio deJ aneiro, observando, também, que os valores da porosidade diminuíam em profundidade, coincidindo com a diminuição dos teores de matéria orgânica.

\section{Propriedades Químicas}

Os teores de carbono orgânico nos Gleissolos foram el evados, consi derando que são sol os mi nerais, como pode ser observado no quadro 3 . O valor mais alto de carbono orgânico para estes solos foi observado no horizonte superficial do perfil $1 \mathrm{com}$ teor de 109,68 $\mathrm{g} \mathrm{kg}^{-1}$, sendo enquadrado como horizonte mineral pela relação C\% $<8+0,067 \times \%$ de argila (EMBRAPA, 1999).

Este teor de carbono orgânico foi, entretanto, suficiente para enquadrar o horizonte no conceito de horizonte hístico do novo sistema, que admite o horizonte superficial que, após revolvido, apresente nos primeiros $25 \mathrm{~cm}$ teor de carbono orgânico segundo a relação C\% $\geq 5,3+(0,088 \times$ \% argila).

Os Organossolos, por definição, apresentam teores elevados de car bono orgânico, que enquadram os horizontes superficiais no conceito de horizonte hístico. A subdi visão dos Grandes Grupos, Sáprico e Hêmico, foi, entretanto, feita morfologicamente de acordo com a escala de decomposição de von Post (Stanek \& Silc, 1977, citado por EMBRAPA, 1999).

Nos seis perfis estudados, opH apresentou a reação extremamente ou fortemente ácida em todos os horizontes (Quadro 3). Nos horizontes subsuperficiais, os val ores de $\mathrm{pH}$ inferiores a 3,5 associados a teores de sulfato solúvel superiores a $500 \mathrm{mg} \mathrm{kg}^{-1}$ (Quadro 3) definiram estes horizontes como horizontes sulfúricos. Os horizontes sulfúricos ocorreram a partir de $45 \mathrm{~cm}$, nos Gleissol os, ea partir de $15 \mathrm{~cm}$, nos Organossolos.

A capacidade de troca de cátions é muito alta em todos os perfis em virtude dos al tos níveis de matéria orgânica. Hidrogênio e alumínio são os cátions dominantes, conferindo caráter distrófico aos perfis 2, 3 e 6, e álico aos perfis 1, 4 e 5 (Quadro 3), no $5^{\circ}$ nível categórico definido pela EMBRAPA (1999).

No quadro 3, encontram-se os valores da condutividade elétrica dos perfis estudados, que apresentaram valores elevados (C.E. $\geq 4,0 \mathrm{dS} \mathrm{m}^{-1}$ ) apenas em alguns dos horizontes sulfúricos. Tais valores, entretanto, não estão relacionados com a salinidade, mas, sim, com o hidrogênio em solução liberado pela oxidação da pirita com formação de ácido sulfúrico (Souza J unior, 1999). Esta afirmação pode ser corroborada pela figura 3, que mostra as correlações significativas entre a condutividade elétrica e os teores de íons sulfato, hidrogênio e pH, bem como a correlação entre sulfato e hidrogênio. Por outro lado, as observações morfológicas não constataram a presença de eflorescências salinas nestes solos.

\section{Classificação e gênese dos Solos}

Os sol os estudados for am sel ecionados com base no Levantamento Detal hado de Solos das Várzeas da U sina Coruripe, em áreas de ocorrência de sol os então classificados como Glei Tiomórficos e Orgânicos Tiomórficos (Usina Coruripe, 1997).

A partir dos dados morfológi cos, físicos equímicos obtidos neste trabalho (Quadros 1, 2 e 3), os seis perfis descritos foram reclassificados, segundo critérios mais recentes, estabelecidos no novo Sistema Brasileiro de Classificação de Solos (EMBRAPA, 1999).

Os solos foram classificados a nível de família (Quadro 1), confirmando a classificação definida no Levantamento Detal hado (Usina Coruripe, 1997). As diferenças observadas dizem respeito à nova nomenclatura e estruturação das classes nas 
Quadro 3. Complexo sortivo; saturação por bases e alumínio; sulfato solúvel, pH, condutividade elétrica e carbono orgânico dos solos

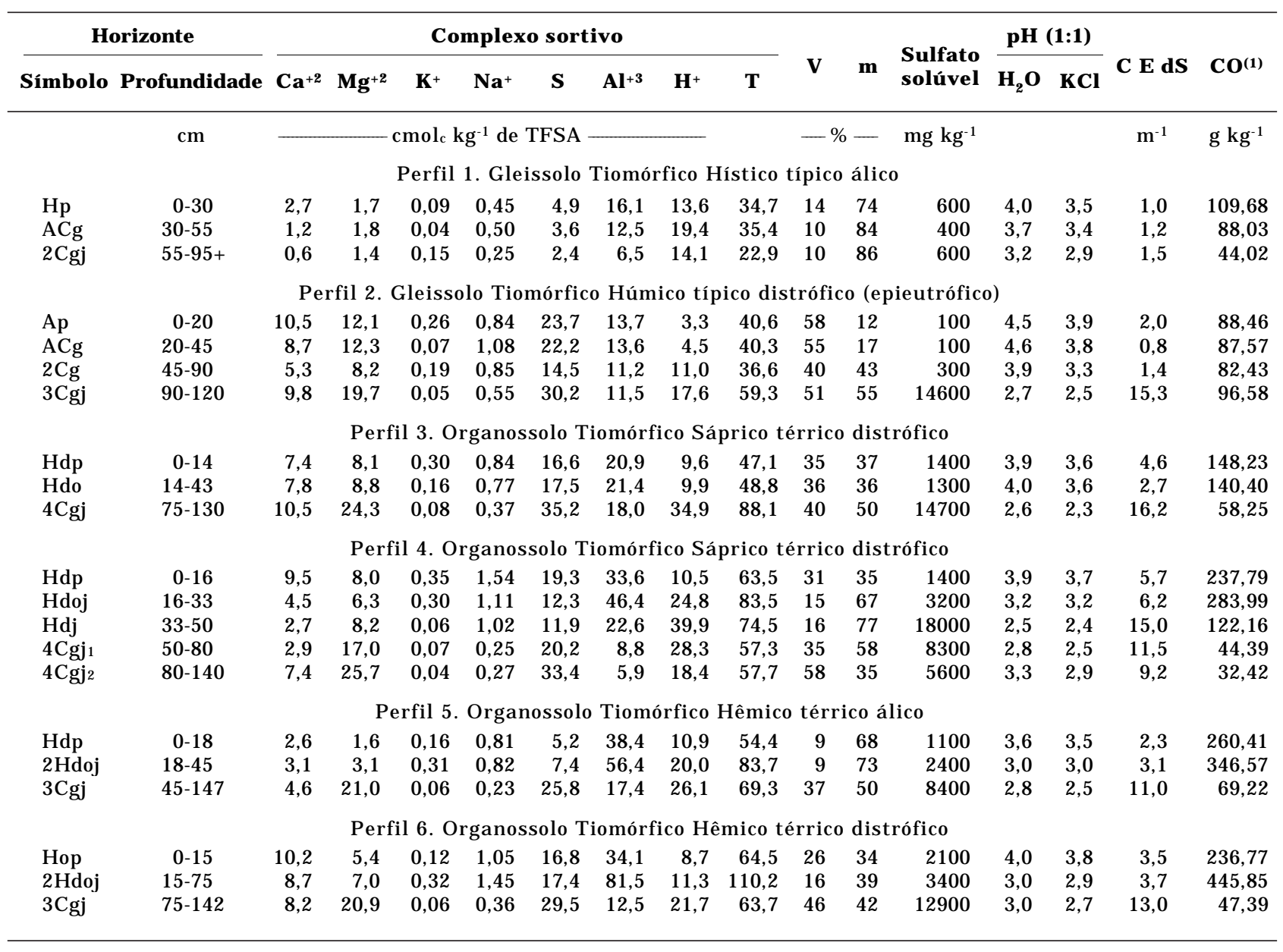
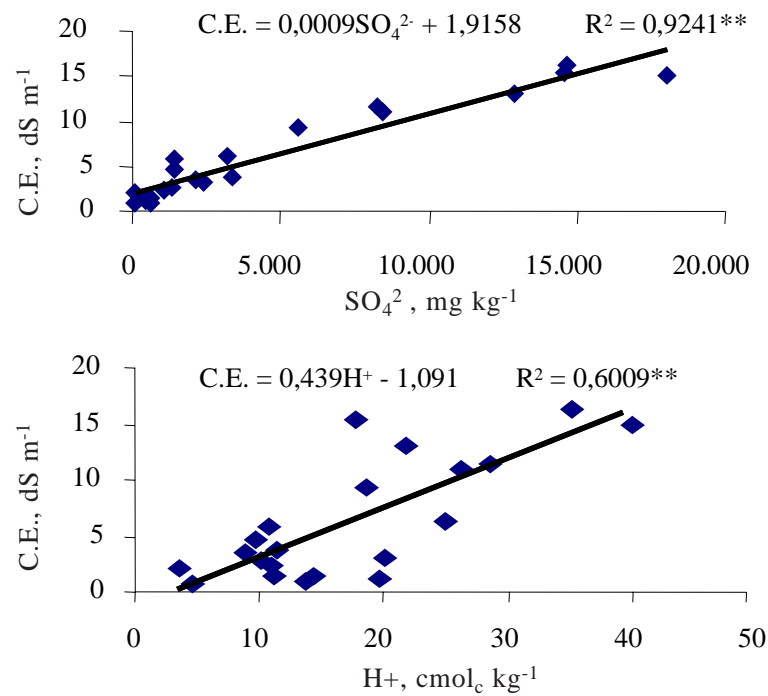
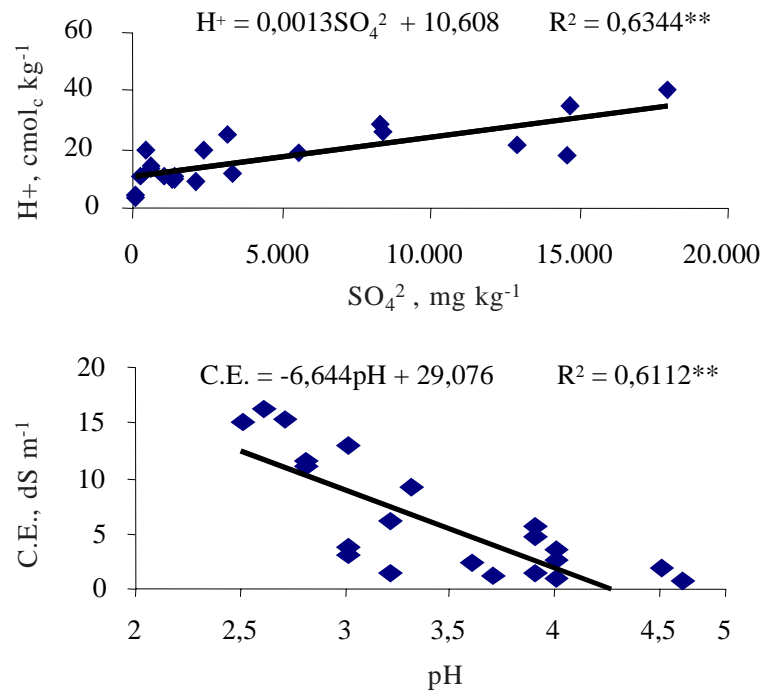

Figura 3. Correlações entre: sulfato solúvel e condutividade elétrica (a), sulfato solúvel e hidrogênio trocável (b), hidrogênio trocável e condutividade elétrica e pH e condutividade eletrica (d) em solos tiomórficos da várzea do rio Coruripe (AL). 
diversas categorias doSistema. Algumas diferenças foram também observadas em conseqüência das novas definições eespecificações para enquadramento nos diversos horizontes diagnósticos superficiais.

Os solos tiomórficos, também conhecidos como solos ácidos sulfatados, desenvol vem-seem sedimentos costeiros sob condições de hidromorfismo, bem como em fundos de lagoas onde existam altos teores de sulfatos. A gênese destes sol os apresenta duas etapas fundamentais para seu desenvolvimento: acumulação inicial de sulfeto de ferro, especialmente pirita, sob condições de redução, e oxi dação da pirita após drenagem dos solos (Seiler, 1992).

Na várzea do baixo curso do rio Cururipe, os sol os tiomórficos estão relacionados com as posições de pior drenagem, mais baixas e mais próximas ao mar, que reúnem ou reuniam as condições essenciais para acumulação da pirita que, segundo Pons \& Van Breemen (1982), são: influência da água do mar para fornecer sulfatos, acumulação de materiais orgânicos e bactérias redutoras de sulfato.

De acordo com Fanning \& Fanning (1989), o processo desulfi di zação ocorre em sol os e sedi mentos ao longo da costa marinha, onde a água do mar, que contém em torno de $900 \mathrm{mg} \mathrm{L}^{-1}$ de sulfato, constitui a fonte de fornecimento de enxofre. O sulfato é reduzido a sulfeto por bactérias na oxidação da matéria orgânica e o ferro provém dos óxidos livres nos sedimentos.

Tendo em vista que a várzea estudada não sofre atualmente a influência das marés e que durante o Quartenário os oceanos ocuparam posição de nível bem mais alta que a atual (Bittencourt et al., 1983), pode-se deduzir que o processo de sulfidização nos solos estudados ocorreu neste período, quando a água do mar foi a fonte fornecedora de sulfatos. Esta constataçãotambém foi feita por Dent \& Pons (1995), que afirmaram ser a recuperação do nível do mar no Holoceno responsável pela formação de solos tiomórficos em várias áreas do mundo, podendo o processo de sulfurização ocorrer nos materiais sulfidricos seestes forem drenados em conseqüência delevantamentos tectônicos ou regressões marinhas.

Considerando os estádios que ocorrem no processo de sulfurização, definidos por Fanning \& Fanning (1989), os sol os da área estudada, antes da instalação do sistema de drenagem, estavam no estádio de pré-sulfurização, em que a oxidação dos materiais sulfidricos está ini bida devidoà saturação contínua com água. Apesar da drenagem natural provocada pela última regressão marinha, as condições de encharcamento da várzea foram mantidas pelo fluxo deágua proveniente do sopé dos Tabuleiros que limitam a várzea e que comandam a alimentação do lençol freático (Figura 1). Esta condição foi provavel menteresponsável pelos baixos níveis de salinidade observados nos solos da área em relação aos níveis comumente observados em outras áreas de sol os tiomórficos, como na região de
Campos (Alves, 1997). A lavagem de sais solúveis destes solos provavel mente iniciou-se com a última regressão do oceano para a posição atual, de nível insuficiente para atingir estas áreas. Com o rebaixamento do nível de base, a cal ha do rio passou a funcionar como um dreno natural, resultando em um fluxo de água que promoveu a lavagem dos sais solúveis.

Com a instalação do sistema de drenagem em 1995, os sol os entraram no processo de sulfurização ativa (Fanning \& Fanning, 1989), atingindo valores de $\mathrm{pH}<3,5$, mais de $500 \mathrm{mg} \mathrm{kg}^{-1}$ de sulfato solúvel e desenvolvimento de mosqueados de cor bruno forte, provavel mente de jarosita, que caracterizam o horizonte sulfúrico (E MBRAPA, 1999), responsável pelo enquadramento dos solos como Gleissolos e Organossol os Tiomórficos.

\section{CONCLUSÕES}

1. As diferenças entre os perfis estudados foram uma conseqüência da posi ção dos sol os na paisagem, compreendendo principalmente a espessura, o teor de carbono e o grau de decomposição do material orgânico dos horizontes superficiais.

2. Os horizontes sulfúricos ocorreram a profundidades de 45 a $90 \mathrm{~cm}$, nos Gleissolos, e de 15 a $43 \mathrm{~cm}$, nos Organossolos, demonstrando a mel hor condição de drenagem dos primeiros.

3. Apesar dos altos teores de argila dos solos estudados, as propriedades físicas dos horizontes superficiais foram determinadas pela matéria orgânica, que contribuiu com teores que variaram de 15 a $77 \%$ da massa do solo.

4. Os critérios estabelecidos no Sistema Brasileiro de Classificação de Solos mostraram-se adequados à classificação dos sol os estudados.

\section{LITERATURA CITADA}

ALVES, E.A.B. Solos orgânicos salinos tiomórficos: Influência da calagem, sob drenagem controlada, nas características químicas do solo e na produção e composição mineral de Brachiária decumbens, Panicum repens L. ecana-de-açúcar. Campos dos Goytacazes, Universidade Estadual do Norte Fluminense, 1997. 82p. (Tese de Mestrado)

BITTENCOURT, A.C.S.P.; MARTIN, L.; DOMINGUEZ, J.M.L. \& FERREIRA, Y.A. Evolução pal eogeográfica quaternária da costa do estado de Sergipe e da costa sul do estado de Alagoas. R. Bras. Geoc., 2:93-97, 1983.

CONCEIÇÃO, M. Natureza do humus e caracterização de solos com el evado teor de matéria orgânica da região de I taguaíSanta Cruz, RJ . Rio de janeiro, U niversidade Federal Rural do Rio de J aneiro, 1989. 169p. (Tese de Mestrado) 
DENT, D. Acid Sulphate Soils: a baseline for research and devel opment. Wageningen, I nternational I nstitute for Land Reclamation and I mprovement, 1986. 203p. (Public, 39)

DENT, D.L. \& PONS, L.S. A world perspective on acid sulphate soils. Geordema, 67:263-276, 1995.

DEWIS, J \& \& FREITAS, F. Physical and chemical methods of soil and water analysis. Rome, Food and Agriculture Organization of the United nations, 1970. p.233-238. (Soils bulletin, 10)

EMPRESA BRASILEIRA DE PESQUISA AGROPECUÁRIA EMBRAPA - Centro Nacional de Pesquisa de Solos. Manual de métodos de análises de Solo. Rio de J aneiro, 1997. 212p (Embrapa-CNPS,1)

EMPRESA BRASILEIRA DE PESOUISA AGROPECUÁRIA EMBRAPA - Serviço de Produção de Informação - SPI. Sistema Brasileiro de Classificação de Solo. Brasília, 1999. $412 p$.

FANNING, D.S. \& FANNING, M.C.B. Soil morfol ogy, genesis and classification. New York, J ohn Wiley \& Sons, 1989. 395p.

LAMBE, T.W. Soil testing for engineers. New York, Massachusetts Institute of Techonology, 1951. p.15-21.

LANI, J .L. Deltas dos Rios Doce e I tapemirim: Solos, com ênfase nos tiomórficos, água e impacto ambiental do uso. Viçosa, Universidade Federal de Viçosa, 1998. 169p. (Tese de Doutorado)

LEMOS, R.C.\& SANTOS, R.D. Manual de descrição e coleta de solo no campo. 2ed. Campinas, Sociedade Brasileira de Ciência do Solo, 1996. 84p.
KÄMPF, N. \& SCHNEIDER, P. Caracterização de solos orgânicos do Rio Grande do Sul: propriedades morfológicas e físicas como subsídio à classificação. R. Bras. Ci. Solo, 13:227-236, 1989.

OLIVEIRA, J .B.; ACOMINE, P.K.T. \& CAMARGO, M.N. Classes gerais de solos do Brasil: guia auxiliar para seu reconhecimento. J aboticabal, Fundação de Estudos e Pesquisas em Agronomia, Medicina Veterinária eZootecnia, 1992. 201p.

PONS, L.J . Outline of the genesis, characteristics, classification and improvement of acid sulphate soils. In: DOST, H., ed. Acid sulphate soils. Wageningen, I nternational Institutefor Land Reclamation and I mprovement, 1973. v.1. p.3-27.

PONS, L.J . \& van BREEMEN, N. Factors influencing the formation of potential acidity in tidal swamps. In: DOST, H. \& van BREEMEN, H., eds. Acid sulphate soils. Wageningen, I nternational Institute for Land Reclamation and Improvement, 1982. p.37-51.

SEILER, E. Acid sulphate soils - Their formation and agricultural use. Hannover, Institute for Scientic Co-operation, 1992. p.92-110. (Natural Resources and Development, 35)

SOUZA J ÚNIOR, V.S. Caracterização, gênese e manejo de solos tiomórficos da várzea do rio Coruripe, estado de Alagoas. Recife, Universidade Federal Rural de Pernambuco, 1999. 92p.(Tese de Mestrado)

USINA CORURIPE. Levantamento detal hado de sol os (Várzeas) da Usina Coruripe. Coruripe, 1997. 45p. (não plubicado)

ZELAZNY, L.W. \& CARLISLE, V.W. Physical, chemical, elemental and oxygen-containing funcional group analysis of selected Florida Histosols. In: AANDAHL, A.R. et al., eds. Histosols: their characteristics, dassification and use. Madison, Soil Science Society of America, 1974. p.63-78. (Special Publication Series, 6) 